\title{
CRÍTICAS E REALIDADES: O QUE DIZEM OS PROFESSORES DE CIÊNCIAS E BIOLOGIA DE ALTAMIRA-PA?
}

\author{
Carlos Augusto Silva e Silva. Universidade Federal do Pará, Belém - \\ carlosaugusto.s02@gmail.com \\ Dhemersson Warly Santos Costa. Universidade Federal do Pará, Belém - Dhemerson- \\ santos@hotmail.com. \\ Janes Kened Rodrigues dos Santos. Universidade Federal do Pará, Belém. Professora da \\ Universidade Federal do Pará (UFPA) - kened@ufpa.br
}

\begin{abstract}
RESUMO: O objetivo desta pesquisa foi delinear o perfil de formação dos professores de Ciências e Biologia, suas necessidades formativas e as principais dificuldades enfrentadas por estes profissionais ao ministrar suas aulas. Para tal, foi aplicado um questionário para os professores da rede municipal e estadual de ensino do município de Altamira-PA, possuindo caráter descritivo. Como resultados, identificou-se que os docentes são, na sua maioria, constituídos por profissionais do sexo feminino formados na área de Ciências Biológicas ou Ciências Naturais, estes apontam algumas deficiências em sua formação com relação ao enfoque docente, como a falta de: práticas pedagógicas mais ativas no período da graduação que incentivassem maior contato com o âmbito escolar, e ajudasse lidar com as situações educacionais contemporâneas. No entanto, em relação aos aspectos teóricos e científicos, estes professores assinalam contentamento com as habilidades desenvolvidas neste quesito. Com relação à infraestrutura, de modo geral, os cursos deixam a desejar, pois se nota falta de laboratórios, estrutura física completa e entre outros. Sabe-se da importância de ter uma boa qualificação na formação inicial de professores, assim como, processos de formação continuada para que estes tenham oportunidades de atualizar-se, utilizando estratégias didáticas, afim de que suas aulas sejam satisfatórias para aprendizagem dos alunos.
\end{abstract}

Palavras-chave: formação de professores, educação básica, necessidades.

\section{REVIEWS AND REALITIES: WHAT THEY SAY THE TEACHERS OF SCIENCE AND BIOLOGY FROM ALTAMIRA - PA?}

\begin{abstract}
The objective of this research was delineate the formation profile of the teachers of science and biology, their training needs and the main difficulties faced by these professionals to minister their classes. For such, a questionnaire was applied to the teachers of the municipal and state education from the county of Altamira - PA, having descriptive character. As a result, it was found that teachers are mostly constituted by female professionals formed in the area of Biological Sciences or Natural Sciences, these point to some shortcomings in their training with regard to teaching approach, like the lack of: more active pedagogical practices in undergraduate period that would encourage greater contact with the school environment and help to deal with contemporary educational situations.
\end{abstract}




\section{V, 13, n.1: 2017}

However, in relation to the theoretical and scientific aspects, these teachers indicate satisfaction with the skills developed in this regard. Regarding the infrastructure in general, the courses are disappointing, because it's visible the lack of laboratories, complete physical structure, among others. We know the importance of having a good qualification in initial teacher training, as well as, continuous education processes so that they have opportunities to upgrade, using didactic strategies, so that their classes are satisfactory on student learning.

Key-words: Teacher training. Basic education. Needs.

\section{INTRODUÇÃO}

Fala-se com frequência, que um dos principais problemas da realidade educacional, é que grande parte dos professores são inseridos neste sistema com baixo padrão de conhecimentos referentes à atuação profissional do professorado (LIMA; VASCONCELOS, 2008).

Há diversos cursos de licenciaturas ${ }^{1}$ espalhados pelo território brasileiro, porém, com currículos extremamente desatualizados e com práticas tendenciosas para a formação de aplicações em pesquisas científicas de natureza biológica, ignorando a formação de um professor pesquisador e reflexivo sobre suas práticas (CUNHA; KRASILCHIK, 2000; CARVALHO; GIL-PEREZ, 1992).

Historicamente, o legado dos cursos em formação de professores em Ciências e Biologia, em diversas partes do país, fundamentaram-se de maneira técnica, enfatizando a teoria e com pouca atividade prática aplicada ao ensino. As atividades eram muito mais descritivas do que realmente construtivas, muito mais profissionalizante que pedagógicas no que tange diretamente ao ofício e fazer docente (BORGES; LIMA, 2007).

Como herança do século anterior, a formação de professores se baseava no modelo do programa de formação de professores $3+1$, que consistia na prorrogação de mais um ano nos cursos de bacharelado. Os interessados no magistério prosseguiriam esse último período do curso com disciplinas pedagógicas que lhes dariam a obtenção da licenciatura, podendo assim, atuarem não apenas como pesquisadores, bem como professores (GATTI, 2010).

Esse modelo perdurou até a década de 60, onde foi fortemente criticado por fazer uma clara separação entre o saber científico e o conhecimento pedagógico, o qual ainda se

\footnotetext{
${ }^{1}$ Neste caso, vale ressaltar, que os cursos referidos são aqueles inerentes à licenciatura em áreas de cunho científico como: biologia; química; física.
} 


\section{V, 13, n.1: 2017}

reflete atualmente nos cursos de licenciatura, com a fragmentação da teoria e a prática (AZEVEDO et al., 2012).

A profissão docente tem sido remodelada através da inclusão de políticas públicas para a formação inicial de professores, como a Lei de Diretrizes e Bases da Educação Nacional $n^{\circ}$ 9.394/96 que definiu e redirecionou o novo estilo profissional dos professores da educação básica, por exemplo, exigindo o curso superior de Licenciatura/Graduação Plena ou Pedagogia para tornar-se atuante, a inclusão de uma carga horária destinada à prática do futuro professor na sala de aula, através dos estágios supervisionados (SPIES; FISS, 2013).

No entanto, mesmo com estas mudanças histórica, o modelo de formação de professores para educação básica no Brasil é um assunto de crítica por pesquisadores (CARVALHO; GIL-PERES，1993; MENEZES，1996; CUNHA; KRASILCHIK，2000; CARVALHO; GIL-PEREZ, 1992; GOUDERT et al., 2003; GARRIDO; CARVALHO, 1999). Dentre estes, Goudert et al. (2003) asseveram que os cursos de licenciaturas no modo geral não propiciam subsídios necessários para os discentes atuarem em suas diversas ações e estratégias em sala de aula, notando um disparate entre a formação e a prática escolar.

É neste contexto de inquietações que o presente estudo propõe apontar as necessidades formativas identificadas pelos professores a partir da prática pedagógica realizada, as críticas e considerações sobre possíveis mudanças nos cursos de formação de professores desta área, assim como, o perfil dos sujeitos da pesquisa.

\section{PROCEDIMENTOS METODOLÓGICOS}

A proposta teórica e metodológica da pesquisa tem cunho qualitativo de Ludke e André (1986), na perspectiva de entender e interpretar o contexto do problema (DANTAS; CAVALCANTE, 2006).

Quanto ao objetivo, a investigação possui caráter descritivo, o qual tem como base apontar as características, fatos e fenômenos, de um determinado grupo ou população, buscando esclarecer ideias, conceitos e formular hipóteses para estudos posteriores (OLIVEIRA, 2011). De acordo com Piana (2009), no que concerne aos procedimentos deste estudo, ele se caracteriza como pesquisa de campo, desenvolvendo-se através da busca da informação de modo direto e objetivo, se reportando ao local onde ocorre o fenômeno a ser estudado. 


\section{V, 13, n.1: 2017}

Para a realização efetiva da pesquisa, foi estabelecida uma parceria com a Secretaria Municipal e Estadual de Educação de Altamira-PA ${ }^{2}$. Em que se efetivou um mapeamento com os professores de Ciências e Biologia que atuam na rede pública (Ensino Fundamental Maior e Médio) até o primeiro semestre de 2015, totalizando 26 professores, sendo que apenas 21 aceitaram contribuir com a pesquisa. Destarte salientar que o referente estudo foi devidamente submetido à apreciação do comitê de ética, em conformidade com a resolução n466/2012.

Para coleta de dados, foi elaborado um questionário estruturado com perguntas abertas e fechadas, obtendo-se registros que permeavam sobre o perfil profissional dos entrevistados, bem como o nível de satisfação com a formação recebida, referente à preparação para atuação profissional. As categorias norteadoras deste instrumento foram assim estabelecidas:

a) Perfil de formação e atuação: instituição que cursou o ensino superior, tempo de magistério, disciplinas que ministra atualmente, série do público que trabalha.

b) Preparo para o exercício profissional, considerando a satisfação com a formação conceitual específica (natureza científica) e aplicada (prática docente): níveis de satisfação com a graduação em Ciências Biológicas, considerando os aspectos inerentes ao preparo para o exercício docente referente ao conhecimento em Biologia aplicada e à prática de ensino.

c) Crítica e sugestão de mudança nos cursos de formação de professores de Ciências e Biologia: fatores imprescindíveis no curso de licenciatura em Ciências Biológicas.

A interpretação dos dados fundamentou-se no embasamento teórico da Análise de Conteúdo, em que se empregou a leitura da mensagem textual para compreensão de sentidos pré-construídos, não se detendo apenas a uma leitura superficial do texto, mas, sobretudo, tentar entender o que o sujeito idiossincrático revela através de suas expressões, podendo também, categorizar tais informações, que são nomeadas por Bardin como unidades de texto (CAREGNATO; MUTTI, 2006; ROCHA; DEUSDARÁ, 2005).

Para a construção das categorias prescritas nos parágrafos posteriores, foram realizados três procedimentos integrados a Análise do Conteúdo Bardin (1977): pré-análise; descrição; tratamento dos resultados e interpretação.

\footnotetext{
${ }^{2}$ O presente estudo foi devidamente autorizado pela Secretária de Educação do Estado do Pará (SEDUC/PA), através do memorando $n^{\circ}$ 1024/2014.
} 


\section{V, 13, n.1: 2017}

Durante todo o processo foi mantido anonimato dos entrevistados, sendo atribuído a eles código de acordo com a ordem de entrevista, como E1, E2, E3 e assim sucessivamente.

\section{RESULTADOS E DISCUSSÃO}

\section{Perfil de atuação dos professores}

No que se refere os dados coletados e analisados, observou-se que grande parte dos entrevistados tiveram sua formação acadêmica inicial na Universidade Estadual do Pará, um percentual de 57\% (12 sujeitos), o restante 33\% (7 sujeitos) formado pela Universidade Federal do Pará e 10\% (2 sujeitos) teve sua formação inicial em outras instituições.

Em relação ao tempo de trabalho, 40\% (8 sujeitos) atuam na área há mais de 15 anos, $40 \%$ (8 sujeitos) possui 10 anos e 20\% (5 sujeitos) tem em média 5 anos de profissão. Há predominância do sexo feminino, cerca de $80 \%$ (16 sujeitos).

Quanto à atuação desses sujeitos, os dados apontam que 57\% (12 sujeitos) lecionam somente a disciplina de Ciências para alunos do ensino fundamental e 14\% (3 sujeitos) trabalham com a disciplina de Biologia no ensino médio. Os demais, um total de 29\% (6 sujeitos) trabalham tanto no ensino de Ciências (fundamental) quanto no de Biologia (médio).

Percebe-se que grande parte dos sujeitos tiveram suas formações em Universidades Públicas, e que estes estão atuando diretamente na educação básica, seja ela, fundamental maior ou ensino médio. Tal perfil é de grande relevância para pensar como estas instituições públicas formaram seus alunos, tendo um panorama geral de como esta formação influenciou nas suas práticas docentes atuais, as quais serão discutidas com maior riqueza nas próximas categorizações.

\section{Preparo para o exercício profissional: satisfação com a formação específica (natureza científica) e aplicada (prática docente)}

Evidenciamos nesta categoria as críticas dos professores quanto à formação inicial recebida a fim de diagnosticar, com base na prática docente, os elementos que deveriam ter na graduação com o propósito de sanar os problemas vivenciados em sala de aula.

Neste sentido, indagamos os docentes quanto à satisfação com a formação inicial recebida no que se refere às temáticas científicas. De uma forma geral os sujeitos demonstraram contentamento com o curso de graduação, haja vista que 55\% (12 sujeitos) 


\section{V, 13, n.1: 2017}

pontuaram como excelente e $45 \%$ ( 9 sujeitos) como boa. Este índice expressivo é corroborado nas unidades de texto dos professores:

"O curso de Ciências Biológicas me deu uma visão ampla de todas as temáticas trabalhadas na graduação" (E2), "Foi abordado bem o conteúdo" (E5), "Tivemos bastante teoria" (E6).

Dominar o conteúdo a ser ministrado, é importante para a construção de um bom professor (PEREIRA; NORNBERG, 2012). Entretanto, "nem sempre quem domina conhecimentos para sua atuação profissional sabe transpô-los para uma situação de aprendizagem" (ALTHAUS, 2004, p.102). Por esse motivo, além dos arcabouços cognitivos referentes à natureza científica que será ensinada, o professor, na sua formação inicial, necessita incorporar outras habilidades para ter sucesso no seu professorado, o que compõe o próximo parágrafo.

Ao serem questionados sobre as estratégias para lidar com a realidade educacional na sala de aula, verificou-se que 77\% (14 sujeitos) indicaram como boa, 16\% (3 sujeitos) como excelente e apenas $1 \%$ (1 sujeito) como insuficiente. No entanto, percebemos que no aspecto que tange o preparo pedagógico didático dos professores, há certo descontentamento implícito, quando equiparado ao domínio específico dos conteúdos da área de conhecimento. Tracejado nesta categoria, obtemos índices expressivos e corroborados nas unidades de textos:

\footnotetext{
"Poderia haver mais prática desde o começo do curso, não só nos estágios supervisionados" (E17); "Deveria ter tido mais prática na sala de aula" (E16); "Desde o início da graduação já levar o discente para a sala de aula" (E5); "Desenvolver oficinas nas escolas, pois nas mesmas faltam laboratórios e todo material prático” (E1); "Estágios mais práticos" (E2).
}

Saviani (2009) assevera que um dos problemas da formação de professores é a desvalorização das disciplinas pedagógicas, e consequentemente o engrandecimento daquelas que propiciam um maior domínio do conteúdo específico. Este mesmo autor defende que uma das raízes deste desequilíbrio é o professor universitário brasileiro, que deprecia estas áreas repassando percepções negativas para seus alunos, inclusive em suas práticas.

A partir disso, torna-se fundamental observarmos nas políticas para a formação de professores, na abordagem pedagógica curricular da educação básica, elementos 


\title{
V, 13, n.1: 2017
}

contextualizados e inerentes à realidade vivida por eles, que resolvam e façam parte de sua realidade local. A fim de que os professores deixem de ser meros reprodutores de uma concepção tradicional de educação, repetindo práticas defasadas. Mas que possam compreender que vivemos em uma sociedade em que a principal característica é a diversidade, e que os alunos precisam ser formados para atividade social, atuando ativamente nesta e de maneira integral.

\section{Críticas e sugestões para mudanças nos cursos de formação inicial de professores de} Ciências e Biologia

Por fim, foi dado oportunidade aos professores contribuírem com sugestões do que deveria ter em um curso de licenciatura em Ciências Biológicas. Neste sentido, detectamos nos discursos dos entrevistados algumas contribuições acerca da formação e práxis docente empregada na construção do futuro professor durante a graduação e a respeito da estrutura da universidade (desenho curricular, infraestrutura e professores).

No que concerne à prática docente, sugestões são contempladas nos seguintes trechos:

\begin{abstract}
"Os conteúdos quando aplicados deveriam ser mais voltados para a realidade dos alunos" (E4); "Inserir nas aulas pedagógicas e psicológicas como entender o aluno e seus questionamentos” (E5); "Ter maior preparo com a realidade escolar. As metodologias e estratégias de ensino na maioria das universidades são passadas ao acadêmico de forma que não condizem com o que é vivido na comunidade escolar" (E7); "Ter na graduação estratégias diversificadas de ensino" (E8); "Harmonia entre conteúdos teóricos e práticos, tanto da área específica, quanto da pedagógica” (E16).
\end{abstract}

Nota-se nesta categoria, que os professores apontam críticas para que os cursos possam contemplar de forma mais sólida as habilidades na prática docente. Este tem sido um problema enfrentado por muitas licenciaturas, que engrandece exacerbadamente as áreas proeminentes a Ciência aplicada e esquece-se de formar um professor reflexivo contendo arcabouços metodológicos para atuar na transposição didática do conhecimento de maneira acessível e de fácil entendimento (CANDAU, 1997).

Tendo em vista estes dilemas, Gatti et al. (2010) indicam que vários cursos de Ciências Biológicas no Brasil, oferecem cerca de 64,3\% de disciplinas específicas na área de Biologia, e apenas $10,4 \%$ de disciplinas de conhecimentos específicos para trabalhar na 


\section{V, 13, n.1: 2017}

docência, além de cargas horárias referentes a cada uma destas são consideravelmente maior nas específicas e menor nas relativas à docência e educação.

Carvalho e Gil-Perez (1992) defendem que os conhecimentos teóricos acerca da aprendizagem de Ciências são de fundamental importância na construção de um profissional ativo e reflexivo no processo de ensinar. Além de ter uma formação pautada na consolidação de dois preceitos básicos "saber" e "saber fazer" (CARVALHO, 2011).

No que tange a estrutura do curso como um todo (infraestrutura, desenho curricular e professores) detectou-se as seguintes insatisfações:

"Material didático e salas equipadas (confortáveis)"(E2); "Um laboratório contendo todos os itens necessários" (E8); "Laboratório" (E9); "Profissionais qualificados" (E12); "Maior carga horária em prática e pesquisa científica" (E7).

Para Marques et al. (2010) os aspectos estruturais no âmbito universitário podem facilitar ou não o desempenho do graduando, sendo que estes são cruciais para um bom desenvolvimento profissional. Sabemos também, que há uma estreita relação do professor com o aluno, ou seja, professores universitários qualificados tendem a gerar alunos/professores com atributos necessários para o mercado de trabalho, considerando as necessidades contemporâneas evidenciadas pelos que lidam com a realidade atual.

\section{CONSIDERAÇÕES FINAIS}

Além dos aspectos inerentes a infraestrutura do ambiente de trabalho, que é de incumbência do sistema educacional, é direito legal do trabalhador da educação ter condições mínimas para a realização de atividades. Os aspectos formativos foram destacados como essenciais para o exercício docente. Estes foram alvo de críticas dos professores atuantes, como, por exemplo: a baixa ênfase às práticas de ensino na sala de aula e a falta de conhecimento pedagógico aplicado para lidar a realidade escolar. Em contrapartida, estes professores alegam que sua formação no aspecto da natureza científica aplicável em aula, foi satisfatória.

Isto é, os professores se sentem atendidos e preparados na área de conhecimento científico dentro de sua área de formação, mas limitados com relação ao modo de aplicar, ensinar e realizar a transposição deste saber. 


\section{V, 13, n.1: 2017}

O despreparo por parte dos professores, muitas vezes advindos desde o curso de licenciatura, força esses profissionais a usarem a sala de aula, em especial os alunos, como "cobaias de um experimento pedagógico não intencional" que não sabe se de fato dará certo, pois "fazem o que podem", sem muita teoria ou reflexão. Precisamos romper com esse paradigma que perpetua o modelo de escola, professor e aluno tão criticado.

Para que haja uma educação de qualidade é necessário investir na formação desses professores, para que eles consigam utilizar meios diferenciados para transpor esse conhecimento científico para os alunos. Implementando atividades contextualizadas, e que venham contribuir para uma melhor noção da realidade escolar, diversificando as formas de como é repassado o conteúdo para estes estudantes.

Saber sobre o perfil dos professores, o que eles falam sobre as críticas e necessidades, que hoje, sentem falta, pode corroborar na estratégia de pensar novos desenhos curriculares para os cursos em Ciências Biológicas da cidade de Altamira-PA. Portanto, a pesquisa não termina aqui, cabe destrinchar mais possibilidades de fazer entender a educação em Ciências e Biologia na referida região, bem como modelos de mudanças.

A sociedade mudou, os integrantes da escola sabem e percebem isso, no entanto, têm dificuldades de realizar ações de intervenção positiva. Destarte, é preciso rever o modelo dos programas de formação inicial de professores, bem como prestar assistência e assessoria aos que estão na ativa.

\section{REFERENCIAS}

ALTHAUS, M. T. M. Ação didática no ensino superior: a docência em discussão. Teoria e Prática da Educação, v.7, p.101-106, 2004. Disponível em: http://www.maiza.com.br/adm/producao/5.pdf. Acesso em: 14 de março de 20015.

AZEVEDO, R. O. M. et al. Formação inicial de professores da educação básica no Brasil: trajetória e perspectivas. Revista Diálogo Educacional, v. 12, n. 37, p. 997-1026, 2012. Disponível em: <http://www2.pucpr.br/reol/pb/index.php/dialogo?dd1=7214\&dd99=view\&dd98=pb7 > Acesso em 07/06/2015.

BARDIN, Laurence. Análise de conteúdo. Lisboa: Edições 70, 1977. Disponível em: <http://pt.slideshare.net/RonanTocafundo/bardin-laurence-anlise-de-contedo $>$. Acesso em: 07/06/2015.

BORGES, R. M. R.; LIMA, V. M. R. Tendências contemporâneas do Ensino de Biologia no Brasil.Revista Electrónica de Enseñanza de las Ciencias v. 6, p.165-175, 2007. 
V, 13, n.1: 2017

CANDAU, Vera M.; ANHORN, C. T. G. A questão didática e a perspectiva multicultural: uma articulação necessária. In: Reunião Anual da Anped, 22., 2000, Anais. Caxambu, MG, 2000 p. 28. Disponível em: <http://www.dhnet.org.br/direitos/militantes/veracandau/candau_questao_didatica_multicultu ral.pdf>. Acesso em: 22 de abril de 2015.

CAREGNATO, R. C. A.; MUTTI, R. Pesquisa qualitativa: análise de discurso versus análise de conteúdo. Texto Contexto Enferm, v. 15, p. 679-84, 2006. Disponível em: <http://www.scielo.br/pdf/tce/v15n4/v15n4a17>. Acesso em 07/06/2015.

CARVALHO, A. M. P.; PÉREZ, D. G. As pesquisas em ensino influenciando a formação de professores. Revista Brasileira de Ensino de Física. São Paulo, v. 14, p. 247-252, 1992.

CARVAlHO, A. M. P. de, Gil-Pérez, D. Formação de Professores de Ciências: tendências e inovações. $8^{\circ}$ ed. São Paulo: Cortez, 1993, v. 26, 120p.

CARVALHO, A. M. P. de; GIL-PÉREZ, D. Formação de professores de ciências: tendências e inovações. 2011.

CUNHA, A. M. O.; KRASILCHIK, M. A formação continuada de professores de ciências: percepções a partir de uma experiência. In: XXIII Reunião Anual da ANPED, 2000.

DANTAS, M.; CAVALCANTE, V. Pesquisa qualitativa e Pesquisa quantitativa. Recife, PE: Universidade Federal de Pernambuco, 2006. (Trabalho de graduação da Disciplina Métodos e Técnicas de Pesquisa). Disponível em: http:<//pt.scribd.com/doc/14344653/Pesquisa-qualitativa-e-quantitativa $>$. Acesso em 07/06/2015.

GARRIDO, E.; CARVALHO, A. M. P. Reflexão sobre a prática e qualificação da formação inicial docente. Cadernos de Pesquisa, São Paulo, n. 107. p. 149-168, 1999. Disponível em: < http://www.scielo.br/pdf/cp/n107/n107a06.pdf >. Acesso em: 19 de abril de 2015.

GATTI, B. A Formação de professores no Brasil: características e problemas. Educação e Sociedade, v. $31, \quad$ n. 113 , p. 1355-1379, 2010. Disponível em: <http://www.scielo.br/pdf/es/v31n113/16.pdf > . Acesso em 07/06/2015.

GOEDERT, L.; et al. A formação de professores de Biologia e a prática docente - o ensino de evolução. In: IV ENPEC-Encontro Nacional de Pesquisa em Educação em Ciências, 2003, Bauru. Anais. Disponível em: http://fep.if.usp.br/ profis/arquivos/ivenpec/Arquivos/Orais/ORAL012.pdf>. Acesso em 03 Mar. 2015.

Lei de diretrizes e bases da educação nacional, Lei ${ }^{\circ}$ 9.394, de 20 de dezembro de 1996. Diário Oficial [da] República Federativa do Brasil, Poder Executivo, Brasília, DF, v. 134, n. 248, 23 dez. 1996. 


\section{V, 13, n.1: 2017}

LIMA K.E.C., Vasconcelos S.D. O professor de ciências das escolas municipais de recife e suas perspectivas de educação permanente. Science teachers from public schools in Recife and their perspective on continuing education. Ciência \& Educação, v. 14, n. 2, p. 347-364, 2008 .

LUDKE, M; ANDRÉ, M. Pesquisa em educação: abordagens qualitativas. São Paulo: EPU, 1986. Acesso em 07/06/2015. Disponível em: <https://pt.scribd.com/doc/67389090/LUDKEMenga-Pesquisa-em-educacao-abordagens-qualitativas-Sao-Paulo-EPU-1986>. Acesso em: 12 de jun de 2015.

MARQUES, C. S.; PEREIRA, B. A. D.; ALVES, J. N. Identificação dos Principais Fatores Relacionados à Infraestrutura Universitária: uma Análise em uma IES Pública. Revista Sociais e Humanas, v. 23, n. 1, p. 91-103, 2010.

MENEZES, L.C. (org.) Formação Continuada de Professores de Ciências - no âmbito iberoamericano, Autores Associados, NUPES, São Paulo, 1996.

OLIVEIRA, M. F. Metodologia científica: um manual para a realização de pesquisas em Administração. 2011.

Parecer $\mathrm{n}^{\circ}$ 292, de 14 de novembro de 1962. Brasil, 1962.

PEREIRA, I. D. M.; NORNBERG, M. Saberes pedagógicos e a prática do bom professor: O que expressam acadêmicos em estágio dos cursos de Pedagogia e Ciências Biológicas. In: Anped Sul, Seminário de pesquisa em educação da região sul, Anais... 2012. Disponível em: <http://www.ucs.br/etc/conferencias/index.php/anpedsul/9anpedsul/paper/viewFile/1173/566 $>$. Acesso em: 13 de março de 2015.

PIANA, MC. A pesquisa de Campo. Editora UNESP; São Paulo: Cultura Acadêmica, 2009. 233 p. ISBN 978-85-7983-038-9. Disponível em:< books.scielo.org/id/vwc8g/pdf/piana9788579830389-06.pdf>. Acesso em: 15 Agost. 2015.

ROCHA, D; DEUSDARÁ, B. Análise de Conteúdo e Análise do Discurso: aproximações e afastamentos na (re) construção de uma trajetória. Alea: Estudos Neolatinos, v. 7, n. 2, p. 305-322, 2005.

SAVIANI, D. Formação de professores: aspectos históricos e teóricos do problema no contexto brasileiro. Revista brasileira de Educação, v. 14, p. 143, 2009. Disponível em: <http://www.scielo.br/pdf/rbedu/v14n40/v14n40a12.pdf >. Acesso em: 12 de fev 2015.

SPIES, J.; FISS D. M. L;. Identidades Docentes, Charges e Crise do/no Magistério: Efeitos de Sentidos. Reflexão e Ação, Santa Cruz, v. 23, n. 1, p. 100-131, 2015. Disponível em:<file:///C:/Users/aline.nascimento/Downloads/5637-26667-1-PB.pdf>. Acesso em 30 JUL. 2015. 